Article publié par le Laboratoire de Construction en Béton de l'EPFL

\begin{tabular}{|l|l|}
\hline Title: & Punching shear capacity of continuous slabs \\
\hline Authors: & Einpaul J., Ospina C. E., Fernández Ruiz M., Muttoni A. \\
\hline Published in: & ACI Structural Journal \\
\hline DOI & $10.14359 / 51688758$ \\
\hline Pages: & pp. $861-872$ \\
\hline City, country: & Farmington Hills, USA \\
\hline Year of publication: & 2016 \\
\hline Type of publication: & Peer reviewed journal article \\
\hline
\end{tabular}

Please quote as:

Einpaul J., Ospina C. E., Fernández Ruiz M., Muttoni A., Punching shear capacity of continuous slabs, ACI Structural Journal, Farmington Hills, USA, 2016, pp. 861-872. 


\title{
Punching Shear Capacity of Continuous Slabs
}

\author{
by Jürgen Einpaul, Carlos E. Ospina, Miguel Fernández Ruiz, and Aurelio Muttoni
}

Provisions for punching shear design of reinforced concrete slabs are usually calibrated on the basis of results from tests on isolated specimens that simulate the slab zone within the points of contraflexure around a column. However, the punching behavior of interior slab-column connections in actual continuous slabs without transverse reinforcement may be influenced by the effects of moment redistribution and compressive membrane action, which can lead to higher punching strengths and lower deformation capacities compared to those in isolated specimens. This paper discusses these behavioral differences on the basis of experiments performed on symmetric edge-restrained slabs and investigates available test data by means of a numerical model. A simplified calculation method (based on the Critical Shear Crack Theory) that accounts for these effects is also proposed. The calculation model shows consistent agreement with the results of the numerical evaluation and is sufficiently simple to be used in design and assessment.

Keywords: compressive membrane action; continuous slab; interior slab-column connection; Model Code 2010; moment redistribution; punching shear.

\section{INTRODUCTION}

Rules for punching shear design and assessment of reinforced concrete members in common codes of practice (including the most recent ACI $318^{1}$ ) are often based on empirically derived formulas. These formulas are fitted using the results of available experiments that are mostly performed on axisymmetric isolated slab specimens supported on a small column stub. These specimens model the negative (hogging) moment area around a column, support, or loading point (isolated from the rest of the continuous slab), where the only redistribution possible is that between radial and tangential moments. Although such tests are affordable and relatively easy to perform, results of experiments $^{2-7}$ and nonlinear analyses ${ }^{8-10}$ of slabs with rotational and in-plane edge restraints have shown that isolated test specimens may not suitably model the behavior and strength of actual continuous slabs. This is caused by the fact that continuous slabs exhibit two phenomena that cannot appear in isolated specimens, namely redistribution between negative (hogging) and positive (sagging) moments and compressive membrane action (CMA), which may increase the flexural and punching capacity of the slab.

\section{Redistribution between hogging and sagging moments}

The distribution of bending moments in a continuous slab is normally calculated using linear-elastic finite element analysis or other methods that assume linear-elastic slab response. Due to this assumption, the size of the hogging moment area is independent of the load level and can be used as a basis for choosing the size of isolated punching speci- (a)

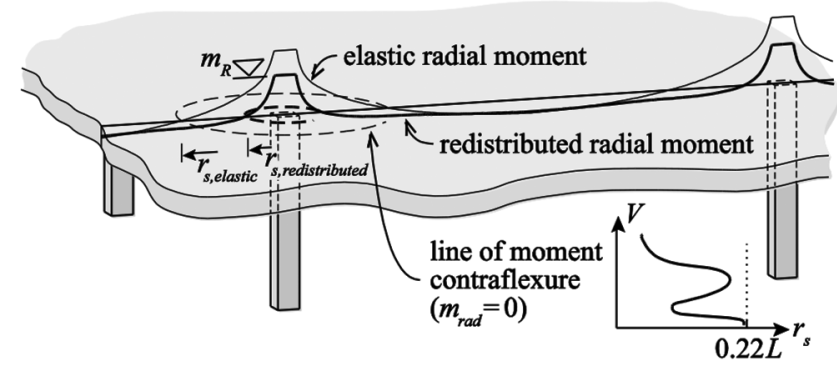

(b)

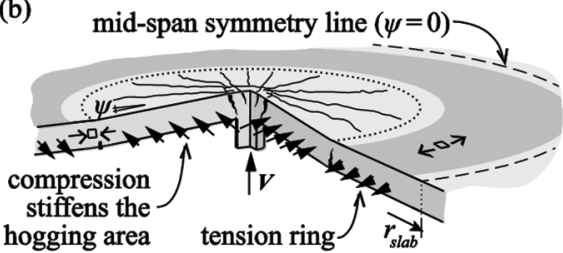

(c)

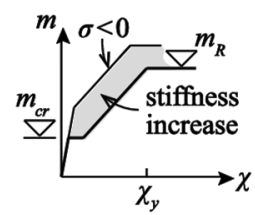

Fig. 1-Behavior of actual slabs: (a) redistribution between hogging and sagging moments in continuous slabs; (b) tangential tension ring arising in continuous slab due to dilation of cracked regions; and (c) influence of normal stress on moment-curvature response of reinforced concrete element.

mens. However, due to cracking of concrete and yielding of reinforcement, the flexural response of reinforced concrete slabs is actually nonlinear and the location of the line of moment contraflexure (at distance $r_{s}$ from the center of the column in Fig. 1(a)) varies with the level of load, as redistribution between hogging and sagging moments takes place. This effect can be experimentally studied only through testing of either continuous slabs or specimens with rotational edge restraints that model a prototype continuous slab up to the midspan symmetry line. As punching shear strength is affected by cracking and deformations of slabcolumn connections, redistribution of moments also has an influence on the shear capacity of the connection. Only a few analytical models for punching address this effect. ${ }^{8,11}$

\section{Compressive membrane action (CMA)}

CMA is a phenomenon where normal forces develop in the slab if its lateral expansion, caused by flexural cracking, is restrained. The actual flexural strength and stiffness of such structures is thus significantly enhanced compared to the predictions of a typical flexural analysis where the occurrence of in-plane forces is neglected. Simple and rational calculation models ${ }^{12-14}$ (acknowledged in some codes of

ACI Structural Journal, V. 113, No. 4, July-August 2016.

MS No. S-2015-262.R1, doi: 10.14359/51688758, was received August 5, 2015, and reviewed under Institute publication policies. Copyright (C) 2016, American Concrete Institute. All rights reserved, including the making of copies unless permission is obtained from the copyright proprietors. Pertinent discussion including author's closure, if any, will be published ten months from this journal's date if the discussion is received within four months of the paper's print publication. 
(a)

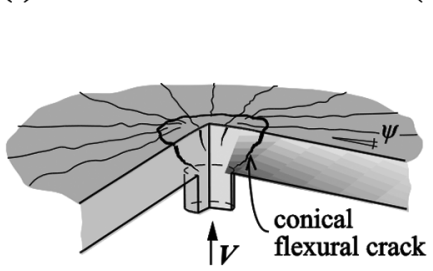

b)

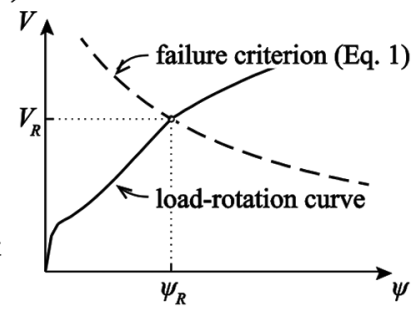

Fig. 2-Approach of CSCT: (a) stress fields and cracks in vicinity of column; and (b) determination of punching load according to CSCT.

practice ${ }^{15}$ ) have been developed on the basis of the theory of plasticity to account for CMA in the cases where the slab is confined between perfectly rigid horizontal supports or where the stiffness of confining elements can be estimated. ${ }^{16}$

CMA also arises in continuous slabs without external confining elements when the lateral expansion of cracked concrete around the column is restrained by the surrounding slab that is still uncracked (Fig. 1(b)) ${ }^{8,17}$ A zone with tangential tensile forces (tension ring) forms in the uncracked (and therefore stiffer) part of the slab. This induces compressive stresses in the hogging moment area that increase its flexural strength and stiffness (Fig. 1(c)). In this paper, this effect is called self-confinement, as it is provided by the surrounding continuous slab itself. This effect appears fully only in the perimeter of internal columns unless the slab has openings close to the column connection. It also appears partially in the case of edge columns but does not appear in corner columns.

\section{Punching of flat plates}

According to experimental observations and theoretical considerations, ${ }^{18-21}$ the punching capacity of a slabcolumn connection is dependent on the state of flexural deformations in the slab in the vicinity of the connection. These approaches allow examining the effects of CMA and moment redistribution on the punching behavior by considering their influence on the flexural deformations, which in turn influence the punching strength. In this paper, such analysis will be performed by using the Critical Shear Crack Theory (CSCT) ${ }^{21}$ According to this approach, the punching strength is influenced by the widths of flexural cracks around the column that propagate to the shearcarrying diagonal compression strut (Fig. 2(a)). The width of this crack is assumed to be proportional to the product of the maximum slab rotation $\psi$ and the effective depth of the slab $d$. Based on this assumption, the following failure criterion was proposed $^{21}$

$$
V_{R}=b_{0} d \sqrt{f_{c}} \cdot \frac{9}{1+15 \frac{\psi \cdot d}{d_{g 0}+d_{g}}}
$$

(U.S. customary units: psi, in.)

For SI units (N, mm), the constant 9 is replaced by 0.75 . Punching failure is predicted to occur when the applied load causes a rotation $\psi$ (that can be determined with any physically based calculation method) that results in a failure load calculated with Eq. (1). This load level $V_{R}$ is graphically represented at the intersection of the load-rotation curve and the failure criterion curve in Fig. 2(b). The failure criterion accounts for size effect by normalizing the product $(\psi \cdot d)$ with a factor $\left(d_{g 0}+d_{g}\right)$, where $d_{g}$ is the maximum aggregate size and $d_{g 0}=16 \mathrm{~mm}(5 / 8 \mathrm{in}$.) is a reference aggregate size. More details about the background of this theory can be consulted elsewhere. ${ }^{22}$ The CSCT is also used as a basis of punching shear provisions in $f i b$ Model Code 2010. ${ }^{23}$

\section{RESEARCH SIGNIFICANCE}

Flexural behavior and punching shear strength of an actual slab may be significantly influenced by redistribution between hogging and sagging moments and compressive membrane action that can occur around interior columns in continuous flat plates, but not in typical isolated punching test specimens. In this paper, these effects are studied on the grounds of experiments on edge-restrained interior slab-column specimens. Based on an axisymmetric numerical model, a new simplified expression is proposed that, in combination with the failure criterion of the CSCT, allows accounting for the enhanced punching shear strength of interior slab-column connections in continuous plates.

\section{BEHAVIOR OF ISOLATED AND CONTINUOUS SLABS}

The flexural behaviors (described by load-rotation curves) of a one-way member (a double cantilever beam), an isolated two-way slab specimen, and a continuous slab (or a slab with flexural edge restraints) under vertical loads are compared in Fig. 3. The curves are calculated using an axisymmetric numerical model proposed by Einpaul et al. ${ }^{8}$ and do not account for CMA. All the compared elements have the same thicknesses and flexural reinforcement ratios. The beam (Fig. 3(b)) and the isolated slab (Fig. 3(d)) have identical values of shear slenderness $\left(r_{q} / d\right.$, where $r_{q}$ is the distance from the load application point to the support). The model of the continuous slab is subjected to uniformly distributed loading and extends to the midspan symmetry line, where the slab rotation is required to be zero. The span of the continuous slab $L$ (Fig. 3(f)) is such that the size of the elastic hogging moment area matches the size of the isolated slab $\left(r_{s}=0.22 L\right)$. The punching load associated with the flexural capacity of each slab $\left(V_{f e x}\right)$ can be found with yield line method with the kinematic mechanisms shown in Fig. 3(b), (d), and (f). The isolated slab has higher flexural capacity than the beam due to the radial plastic hinges that activate the reinforcement in the whole slab (Fig. 3(e)). In turn, the continuous slab has higher flexural capacity than the isolated slab due to a circular plastic hinge that also activates the sagging reinforcement (Fig. 3(g)). It is worth noting that the stiffnesses of the different contributions are not equal and the rotation $\psi_{y}$ at which $V_{\text {fex }}$ is reached varies for the three cases (Fig. 3(a)). Due to the lower stiffness of the sagging mechanism, the load-rotation curves for the isolated and continuous slabs are similar until the first yielding of the hogging reinforcement. After that, however, the stiffness of the hogging mechanism starts to decrease and the difference between the response of the isolated and the continuous slabs becomes more significant. After full yielding of 
(a)

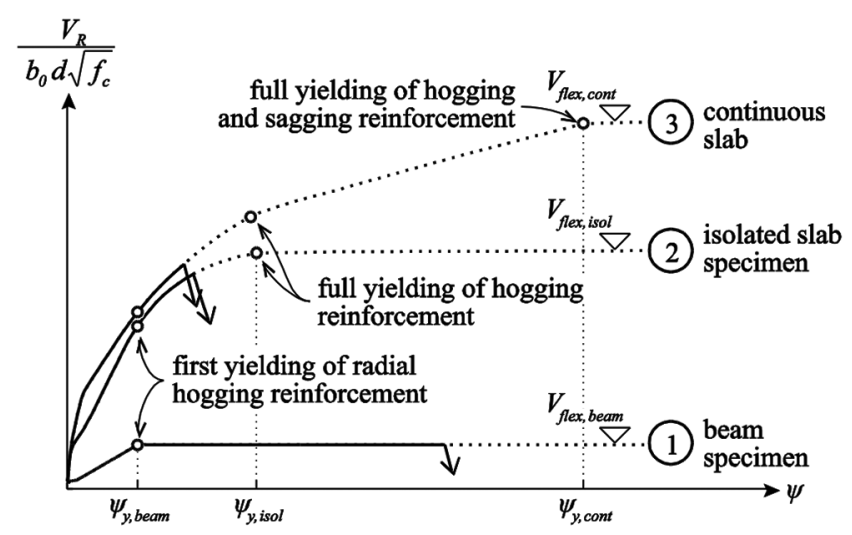

(b)

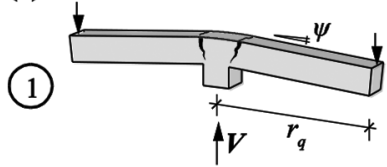

(c)

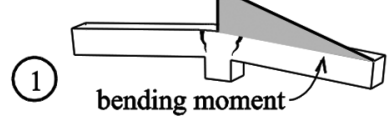

(d)

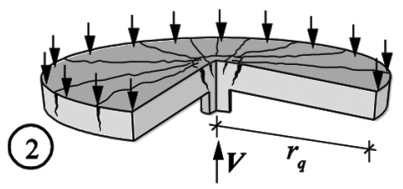

(e)

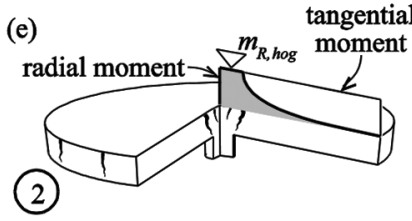

(f)

(g)

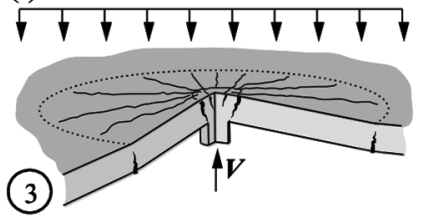

(a)

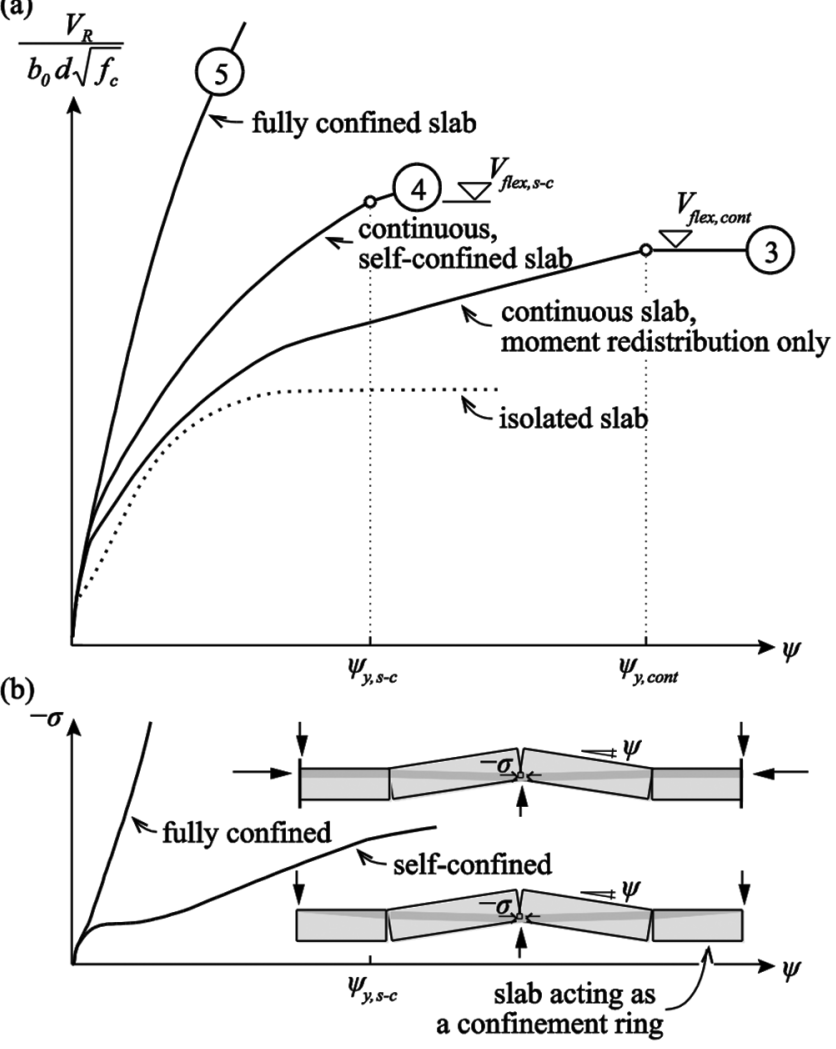

Fig. 4-Influence of full confinement and self-confinement on response of continuous slab: (a) load-rotation relationships; and (b) development of in-plane compressive forces as function of slab rotation.

forcement were activated if CMA was neglected (Fig. 3) cannot be distinguished in confined slabs.

Self-confinement can be modeled by requiring that the in-plane stress in the slab at the midspan symmetry line be zero. In this case, the compressive stress around the slabcolumn connection develops as a function of the stiffness of the tension ring (Fig. 4(b)). This stress is lower than in the fully confined case and due to this, the load-rotation response of self-confined slabs is less stiff than that of fully confined slabs (Curve 4 in Fig. 4(a)).

\section{EXPERIMENTAL INVESTIGATION}

Most punching tests found in literature have been performed on isolated slab specimens that model the hogging moment area of an actual continuous slab. The shear force can be applied by either loading the column while the slab is supported along its edges or by applying the load at the slab edges and supporting the specimen on a column in the center. This type of slab specimens only allows for redistribution between radial and tangential hogging moments (Fig. 3(e)). To also permit redistribution between hogging and sagging moments (that changes the location of the line of moment contraflexure as shown in Fig. 1(a)), multi-span slabs ${ }^{3}$ or members with in-plane and/or rotational restraints along the slab edges ${ }^{4,5}$ have to be tested. One such test, previously unpublished, was performed by the second author at the University of Alberta (Canada) as a part of an experimental study on the punching shear behavior of strengthened/rehabilitated concrete slabs. ${ }^{24}$ Test results using the same setup, 


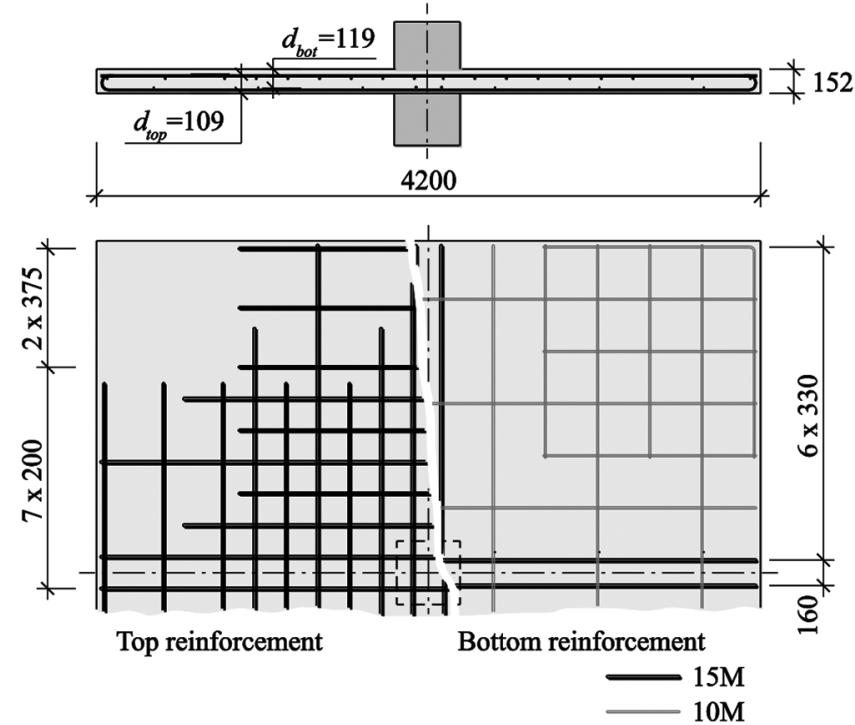

Fig. 5-Reinforcement layout of specimen. (Note: Dimensions in $\mathrm{mm} ; 1 \mathrm{~mm}=0.0394$ in.)

performed by Choi and Kim, ${ }^{7}$ and an experimental campaign by Clément et al. ${ }^{25}$ on specimens with moment applied at the edges, are also analyzed to evaluate the influence of CMA and edge restraints on the punching capacity of slabs.

\section{Test specimen}

Test Slab ER1-VS was square with a side length of $4.2 \mathrm{~m}$ (13.8 ft), thickness $h=152 \mathrm{~mm}$ (6.0 in.), and had a measured average effective depth $d=109 \mathrm{~mm}$ (4.3 in.) and $119 \mathrm{~mm}$ (4.7 in.) for top and bottom reinforcement, respectively. The slab had $400 \mathrm{~mm}$ (15.7 in.) square column stubs in the center protruding $300 \mathrm{~mm}$ (11.8 in.) above and $330 \mathrm{~mm}$ (13.0 in.) below the slab. Mean cylinder (152 x $304 \mathrm{~mm}[6 \times 12$ in.]) concrete strength at the time of testing was $29.8 \mathrm{MPa}$ (4320 psi) and maximum aggregate size $19 \mathrm{~mm}$ (3/4 in.).

The slab flexural reinforcement was designed to comply with the requirements of ACI $318-71^{26}$ in terms of minimum slab thickness and amount of reinforcement as well as distribution of design flexural moments (using the direct design method) and per CSA A23.3-9427 in terms of cutoff points, development length, and integrity steel. Top reinforcement (refer to Fig. 5) consisted of $15 \mathrm{M}\left(A_{s}=200 \mathrm{~mm}^{2}\right.$ [0.31 in. $\left.\left.{ }^{2}\right]\right)$ and $10 \mathrm{M}\left(A_{s}=100 \mathrm{~mm}^{2}\left[0.16 \mathrm{in}^{2}\right]\right)$ bars (with yield strengths of 428 and $441 \mathrm{MPa}$ [62 and $64 \mathrm{ksi}$ ], respectively). The top reinforcement was concentrated in the center of the slab so that the reinforcement ratio varied from $0.92 \%$ within column-wide strips to $0.25 \%$ close to the edges. The bottom reinforcement was more uniformly distributed; the reinforcement ratio was $0.25 \%$, except in the column strips, where two $15 \mathrm{M}\left(A_{s}=200 \mathrm{~mm}^{2}\left[0.31 \mathrm{in}^{2}\right]\right.$ each $)$ integrity bars were placed. However, only half of the bottom bars were continuous along the whole slab with the other half being cut in the middle. All bottom bars were developed with 180-degree hooks, whereas the top bars had straight ends.

\section{Test setup}

Rotations of the edges of the test slab were restrained by a system consisting of four steel square hollow columns bolted

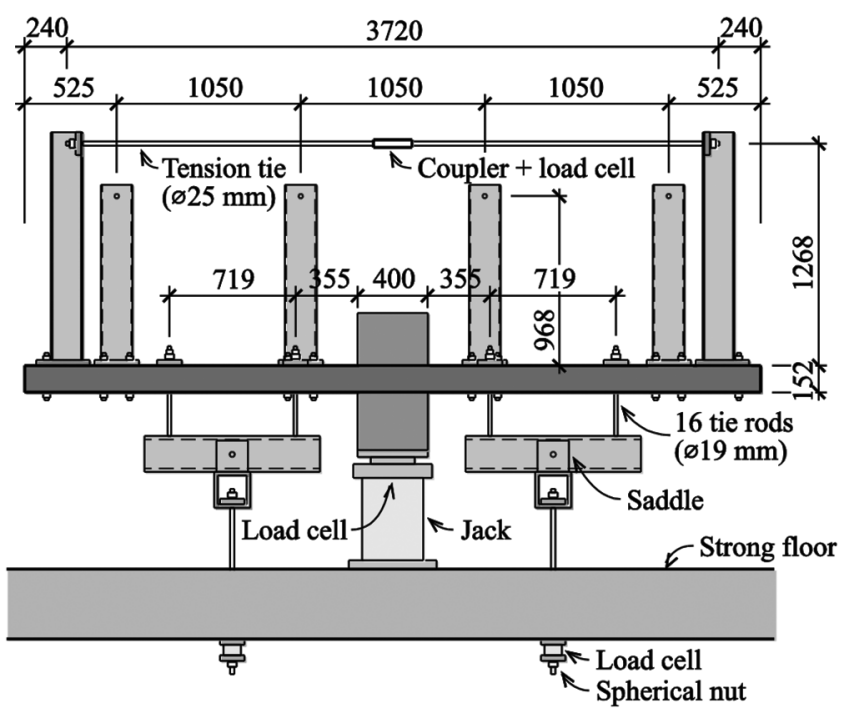

Fig. 6-Test setup. (Dimensions in $\mathrm{mm} ; 1 \mathrm{~mm}=0.0394 \mathrm{in.}$ )

down to the slab along each side and connected at the top with steel tie rods (Fig. 6). The load was applied by jacking up the central column stub and restraining the displacement in 16 equally loaded points.

Prior to the start of the test, the edge restraining system was prestressed to provide a moment distribution similar to that in a corresponding continuous slab under self-weight (assuming that the sections where the steel columns were fixed represented span center lines). Then, the test slab was brought up to punching failure after imposing five load cycles. The cyclic loading intended to simulate conditions in an actual slab due to service loads.

\section{Test results}

A detailed description of the test and the slab response is given by Ospina et al. ${ }^{24}$ The first observed cracks were flexural cracks that formed on the slab top surface at a load of $96 \mathrm{kN}$ (21 kip), barely above the self-weight of the slab and the testing apparatus ( $89 \mathrm{kN}$ [20 kip]). The cracks formed along the two centermost bars of the topmost reinforcement layer. These cracks progressed from the column toward outer slab regions followed by similar cracks along the other axis and reached the edge of the slab at approximately $260 \mathrm{kN}$ (58 kip). This point can be seen as a change in the slope of the load-deflection curve (Fig. 7(a)). The first yielding of top reinforcement according to strain gauge measurements was observed around the column at $386 \mathrm{kN}$ (87 kip) and the first yielding of bottom bars occurred at $448 \mathrm{kN}$ (101 kip). A sudden punching failure took place at a load of $542 \mathrm{kN}$ (122 kip). The crack pattern after the failure is shown in Fig. 7(b).

\section{Comparison of test results to numerical model}

The behavior of Test Specimen ER1-VS was compared to the response calculated with the numerical model. ${ }^{8}$ The geometry of the slab (including the distribution of reinforcement) was assumed to be axisymmetric and top and bottom reinforcement ratios constant over the whole slab (Fig. 8). The influences of rotational edge restraint and CMA were analyzed separately by performing two analyses. At first, 
(a)

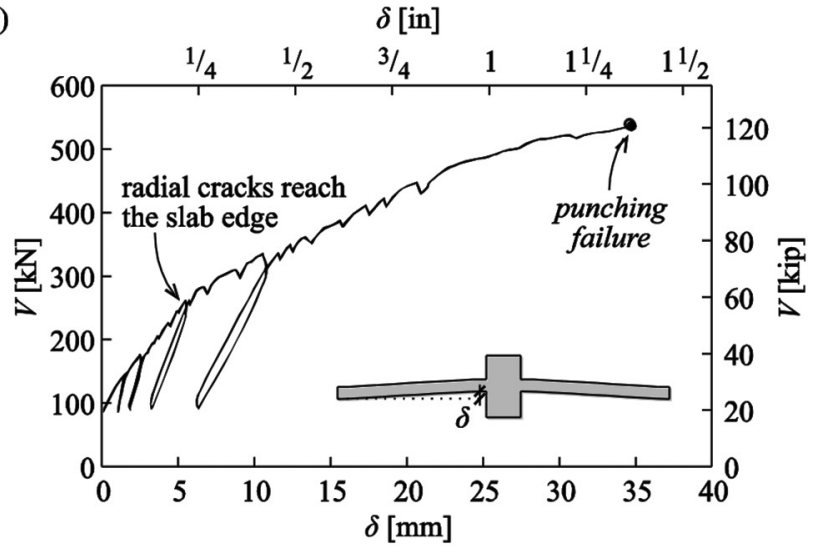

(b)

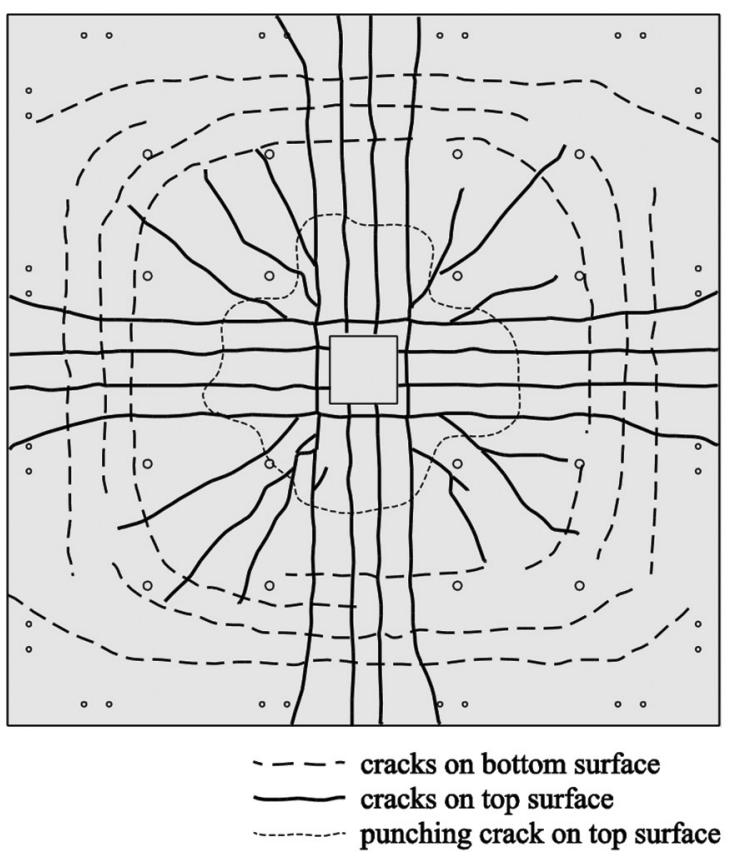

Fig. 7-Specimen ER1-VS: (a) load-deflection response; and (b) cracking pattern after punching failure.

a simpler model was considered that did not account for in-plane forces and deformations. The only applied edge condition was edge rotation (that was required to correspond to the measured value). Therefore, only the effect of redistribution between sagging and hogging moments was modeled. In the second model, the influence of axial deformations due to cracking of concrete and consequent membrane forces (with their influence on axial deformations) were taken into account as well. The second edge condition applied was that the axial force at the edge of the slab was required to be zero (actually, a negligibly small axial compression equal to the force in the tension ties was present in the tested slab).

Figure 9 shows the resulting load-deflection curves from the two analyses together with the observed response curve. Prior to first flexural cracking (predicted at $91 \mathrm{kN}$ [20 kip]), dilation of the slab is zero and no membrane force is generated. Therefore, in this range, both models predict the same response. After cracking, the cracked portion of the slab starts to dilate but the dilation is restrained by the uncracked part of the slab around it. Thus, in the model with CMA, a tension ring develops close to the edge of the slab. This induces compressive forces in the hogging moment

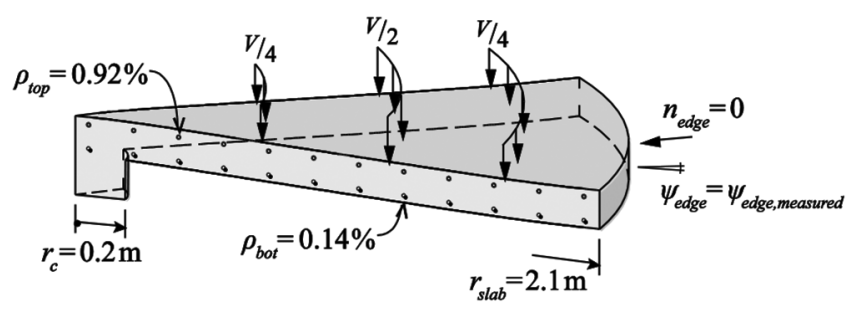

Fig. 8-Axisymmetric numerical model of ER1-VS.

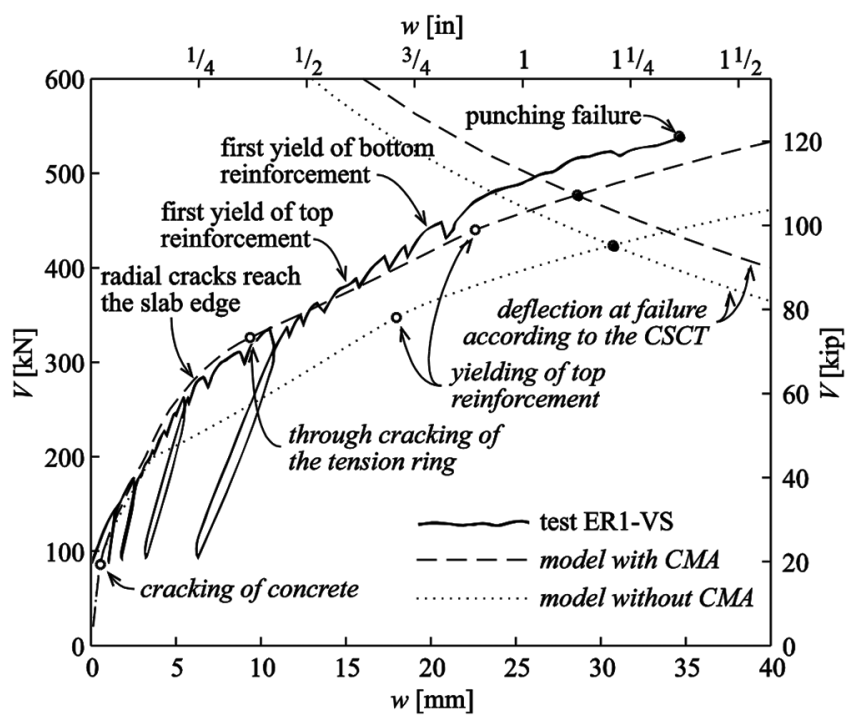

Fig. 9-Comparison of measured and predicted response (Slab ER1-VS).

area, which stiffens the response compared to the model without CMA. At $325 \mathrm{kN}$ (73 kip), stresses in the tension ring reach the tensile strength of concrete over the whole slab thickness, leading to through-cracking of the tension ring. After this, the rate of increase of compressive stress in the hogging moment area decreases significantly. The tangent stiffnesses of the curves are similar, but the second model shows considerably smaller deformations at a given level of load. Yielding of top reinforcement at the face of the column is predicted at $350 \mathrm{kN}$ (79 kip) in the first model and at $440 \mathrm{kN}$ (99 kip) in the second. Punching failure is predicted to occur at the intersection between the response curve and the failure criterion of the $\mathrm{CSCT}^{21}$ (Eq. (1)) at $420 \mathrm{kN}$ (97 kip) when CMA is neglected and at $475 \mathrm{kN}$ (110 kip) when CMA is accounted for. The actual punching failure occurred at $542 \mathrm{kN}$ (122 kip), slightly higher than predicted, possibly due to the effect of compressive stresses in the punching perimeter that are not accounted for in the failure criterion.

A comparison between the observed and predicted load-deflection curves in Fig. 9 shows a very good agreement between the experimental results and the calculation that includes the CMA effect. Differences between the predicted and observed cracking and yielding loads can be explained by the differences between the axisymmetric simplification of the numerical model and the actual geometry, where column corners, orthogonal layout of reinforcement, and load application points can cause concentrations of stresses and deformations. Local stress concentrations may also explain the observed yielding of bottom reinforcement, 
Table 1 -Comparison of test parameters and results of tests by Ospina et al., ${ }^{24}$ Choi and $\mathrm{Kim},{ }^{7}$ and Clément et al. ${ }^{25}$

\begin{tabular}{c|c|c|c|c|c}
\hline Slab & $\rho_{\text {hog, }} \%$ & $\rho_{\text {sag }}, \%$ & $f_{c, \text { cyl }}, \mathrm{MPa}(\mathrm{psi})$ & $V_{R, \text { test }} / b_{0} d{ }_{f_{c}}, \sqrt{\mathrm{MPa}}(\sqrt{\mathrm{psi}})$ & $V_{R, \text { pred }} / b_{0} d \sqrt{ } f_{c}, \sqrt{\mathrm{MPa}}(\sqrt{\mathrm{psi}})$ \\
\hline ER1-VS $^{24}$ & 0.92 & 0.14 & $29.8(4320)$ & $0.469(5.65)$ & $0.411(4.95)$ \\
\hline MRA $^{7}$ & 1.06 & 0.31 & $37.0(5370)$ & $0.345^{*}(4.15)$ & $0.433(5.21)$ \\
\hline MRB & 0.83 & 0.43 & $30.5(4420)$ & $0.327^{*}(3.94)$ & $0.427(5.14)$ \\
\hline MRC & 0.58 & 0.57 & $34.6(5020)$ & $0.335^{*}(4.03)$ & $0.409(4.92)$ \\
\hline PC125 & 0.84 & 1.06 & $44.0(6380)$ & $0.574(6.92)$ & $0.520(6.26)$ \\
\hline PC2 & 1.64 & 1.05 & $45.3(6570)$ & $0.658(7.92)$ & $0.550(6.62)$ \\
\hline PC3 & 0.83 & 2.19 & $43.8(6350)$ & $0.632(7.61)$ & $0.647(7.79)$ \\
\hline PC4 & 1.65 & 2.00 & $44.4(6440)$ & $0.691(8.31)$ & $0.660(7.94)$ \\
\hline
\end{tabular}

${ }^{*}$ Cyclic tests.

although the numerical model does not predict it before the punching failure.

The numerical model predicts the formation of a thoroughly cracked tension ring along the perimeter of the specimen. This effect explains the observed propagation of top surface radial cracks to the specimen's edge, even though the measured edge rotation is small and thus the tangential moment should not cause cracking. The cracks at the edge of the slab at rather low levels of load indicate that a tensile axial force is present in the cross section.

\section{Comparison with other tests}

Choi and $\mathrm{Kim}^{7}$ performed three punching tests on slabs with rotationally restrained edges using the same test setup as described previously. In their slabs, the reinforcement was designed to provide similar flexural strength for all the specimens. However, the selected ratios between the amounts of hogging and sagging reinforcement varied significantly, from 3.5:1 to $1: 1$ (Table 1). Despite this variation, the observed punching strengths for the three specimens were similar. This observation contradicts the predictions of empirical design models (such as the one used in Eurocode 2 punching provisions ${ }^{28}$ ) that have been established on the basis of isolated elements considering only the influence of hogging reinforcement. For the slabs tested by Choi and Kim, ${ }^{7}$ the increase of the amount of sagging reinforcement and CMA were sufficient to compensate for the decrease of hogging moment capacity and provide similar punching shear strengths in spite of the very different hogging reinforcement ratios. It should be noted that the experimental failure loads were consistently lower than predicted, likely due to the influence of the cyclic loading sequence; all specimens failed during cycling the applied load between 80 and 100\% of the maximum load (even a low number of cycles at load levels close to the shear capacity is known to noticeably reduce the shear strength ${ }^{29}$ ).

Clément et al. ${ }^{25}$ performed four tests on square $3 \times 3 \mathrm{~m}$ $(9.8 \times 9.8 \mathrm{ft})$ slabs with thickness of $250 \mathrm{~mm}$ (9.8 in.) (Table 1). Sagging moment was applied at the edges of specimens by means of stiff L-shaped steel elements and hydraulic jacks between them (refer to Fig. 10(a)). Shear force was applied close to the edge of the slab with a separate set of jacks. The moment was increased proportionally to the shear force up to a previously defined limit. ${ }^{25}$ The numerical model predicts the response of the slab with a very satisfactory precision (Fig. 10(b)). It can also be noted that the effect of CMA is less significant in this test series due to the smaller extent of the sagging moment area and therefore a narrower tension ring. A parametric analysis with variable edge moment and a comparison to the test results ${ }^{25}$ on Fig. 10(c) show that for this series, the edge moment has a significant influence on the punching strength and the effect of CMA becomes more significant with increasing edge moment. In addition, due to the beneficial influence of edge moment (sagging moment in actual slabs) and CMA, punching strength of continuous slabs is less dependent on the hogging reinforcement ratio than in the case of isolated specimens without edge restraints (refer to the decreasing gap with increasing edge moment between the curves for $\rho=1.64 \%$ and $0.84 \%$ in Fig. $10(\mathrm{c}))$.

More comparisons between the numerical model and results of experiments with different kind of test setups ${ }^{3,6}$ can be consulted elsewhere. ${ }^{8}$

\section{SIMPLIFIED ANALYTICAL MODEL Load-rotation relationship based on isolated specimens}

According to the CSCT, the punching strength of a slabcolumn connection can be found where a suitable loadrotation curve intersects the failure criterion (Eq. (1)). For continuous or confined plates, the load-rotation curve can be calculated using the presented numerical model. However, for practical applications, a simplified approach is needed. For isolated slab-column connections, Muttoni ${ }^{21}$ proposed a formula for approximating the load-rotation curve on the basis of equilibrium equations and compatibility conditions ${ }^{30}$

$$
\psi=1.5 \cdot \frac{r_{s}}{d} \frac{f_{y}}{E_{s}} \cdot\left(\frac{V}{V_{f l e x}}\right)^{3 / 2}
$$

For practical purposes, the distance between the center of the column and the line of moment contraflexure $r_{s}$ can be estimated using elastic calculations (for slabs with regular bays, a good estimate is $r_{s} \approx 0.22 L$, where $L$ is bay span) and the ratio $V / V_{\text {flex }}$ may be replaced by $m_{S, h o g} / m_{R, h o g}$, where $m_{S, h o g}$ is the average hogging moment in the support strip used for dimensioning reinforcement according to a linear-elastic 
(a)

(b)
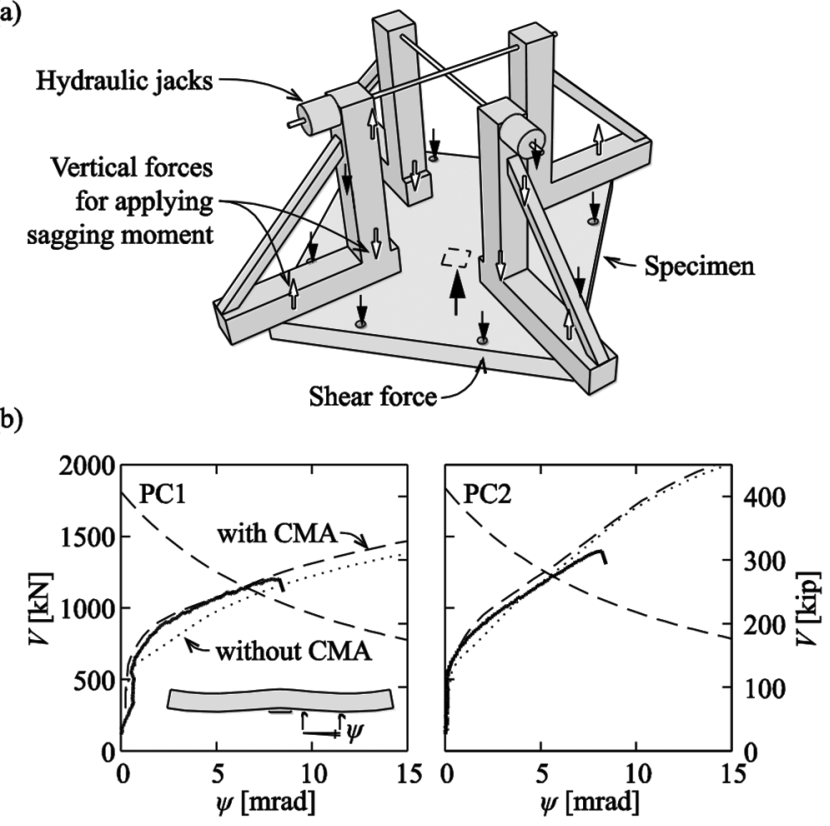

(c)

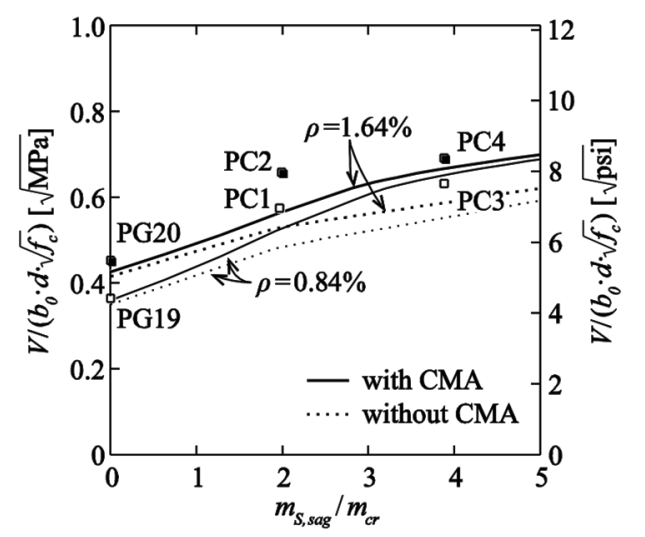

Fig. 10-Tests by Clément et al. ${ }^{25}$ : (a) moment application frame; (b) comparison between test results and numerical model; and (c) punching strength of specimen depending on applied edge moment.

calculation (for inner columns, it can be approximated as $V / 8)$ and $m_{R, h o g}$ is the corresponding flexural strength

$$
\psi=1.5 \cdot \frac{r_{s}}{d} \frac{f_{y}}{E_{s}} \cdot\left(\frac{m_{S, h o g}}{m_{R, h o g}}\right)^{3 / 2}
$$

A possible approach for performing a more refined calculation is adopting values for the parameter $r_{s}$ and the ratio $m_{S, h o g} / m_{R, h o g}$ that account for moment redistribution due to nonlinear behavior and compressive in-plane forces. Figure 11 shows the values of $r_{s}$ and the in-plane compressive stress $-\sigma$ (that increases the flexural strength $m_{R, h o g}$ ) in self-confined slabs depending on slab rotation $\psi$ (using the numerical axisymmetric model of Einpaul et al. ${ }^{8}$ ). The development of $r_{s}$ is shown in Fig. 11(a) through (c) for various amounts of hogging and sagging reinforcement, as well as using different values for concrete tensile strength $f_{c t}$. It can be seen that the line of moment contraflexure is close to the elastic approximation of $r_{s}=0.22 L$ only in the elastic phase before cracking and also in the phase where both hogging and sagging moment areas are cracked and the stiffnesses are therefore similar. The size of the hogging moment area decreases when its stiffness is smaller than that of the sagging moment area-either when only the hogging moment area is cracked or when the hogging reinforcement has reached yielding (at large rotations). Therefore, the isolated approach with $r_{s}=0.22 L$ according to linear calculation provides a safe estimate that may be conservative for low hogging reinforcement ratios or large slab rotations.

The compressive in-plane stress $-\sigma$ (Fig. 11(d) through (f)) only appears after the concrete cracks due to hogging moments in the vicinity of the column. With increasing slab rotation, crack widths increase, thus increasing the confining stresses generated by dilation of the cracked slab portion. The stress level is therefore highly dependent on slab rotation. In this regard, CMA is different from the influence of prestressing that delays concrete cracking and where stress level is not very significantly influenced by slab deformations. The compressive stress is lower in the case of higher hogging reinforcement ratios because then the dilation of the slab is lower (Fig. 11(d)). The compressive stress is also strongly influenced by the tensile strength of concrete because the cracking and stiffness of the tension ring around the hogging moment area is affected by tensile behavior of reinforced concrete members.

Figures $11(\mathrm{~g})$ through (i) show a comparison between the load-rotation curves of isolated specimens (dotted lines) and self-confined continuous slabs (continuous lines), calculated in both cases with a nonlinear axisymmetric model for isolated slabs ${ }^{21}$ but using the $r_{s}$ values from Fig. 11(a) through (c) as element sizes and accounting for the effect of in-plane compression shown in Fig. 11(d) through (f) on flexural response in the case of continuous slabs. The CSCT failure criterion is shown with dashed lines. It can be seen that the differences between continuous and isolated slabs are larger in the case of low amounts of hogging reinforcement. This can be explained by two phenomena. First, the isolated approach overestimates the size of the hogging moment area in slabs with low hogging reinforcement ratios (Fig. 11(a)). Second, due to neglecting the compressive force $-\sigma$ (which is larger in slabs with low amount of hogging reinforcement, as shown in Fig. 11(d)), flexural strength of the hogging moment area is also underestimated. The amount of sagging reinforcement can be seen to have a lower influence on the load-rotation response than the amount of hogging reinforcement (Fig. 11(h)).

\section{Load-rotation relationship for self-confined continuous slabs}

On the basis of comparing slab rotations at the onset of a flexural plateau in an isolated slab ( $\psi_{y, \text { isol }}$ in Fig. 3(a)) and in a continuous self-confined slab ( $\psi_{y, s-c}$ in Fig. 4(a)), the load-rotation relationship of Eq. (3) is modified by reducing the rotations with respect to isolated specimens by a factor $\left(1-2 m_{c r} / m_{R, h o g}\right)$ 
(a)

(b)

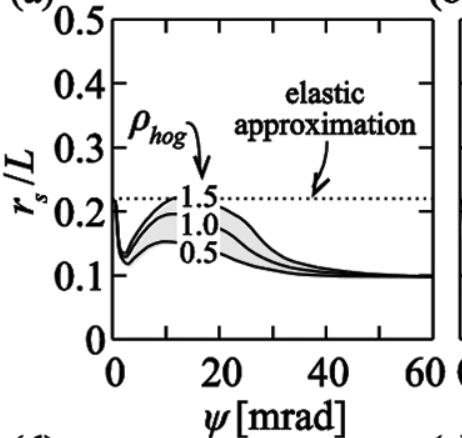

(d)

(e)

(c)
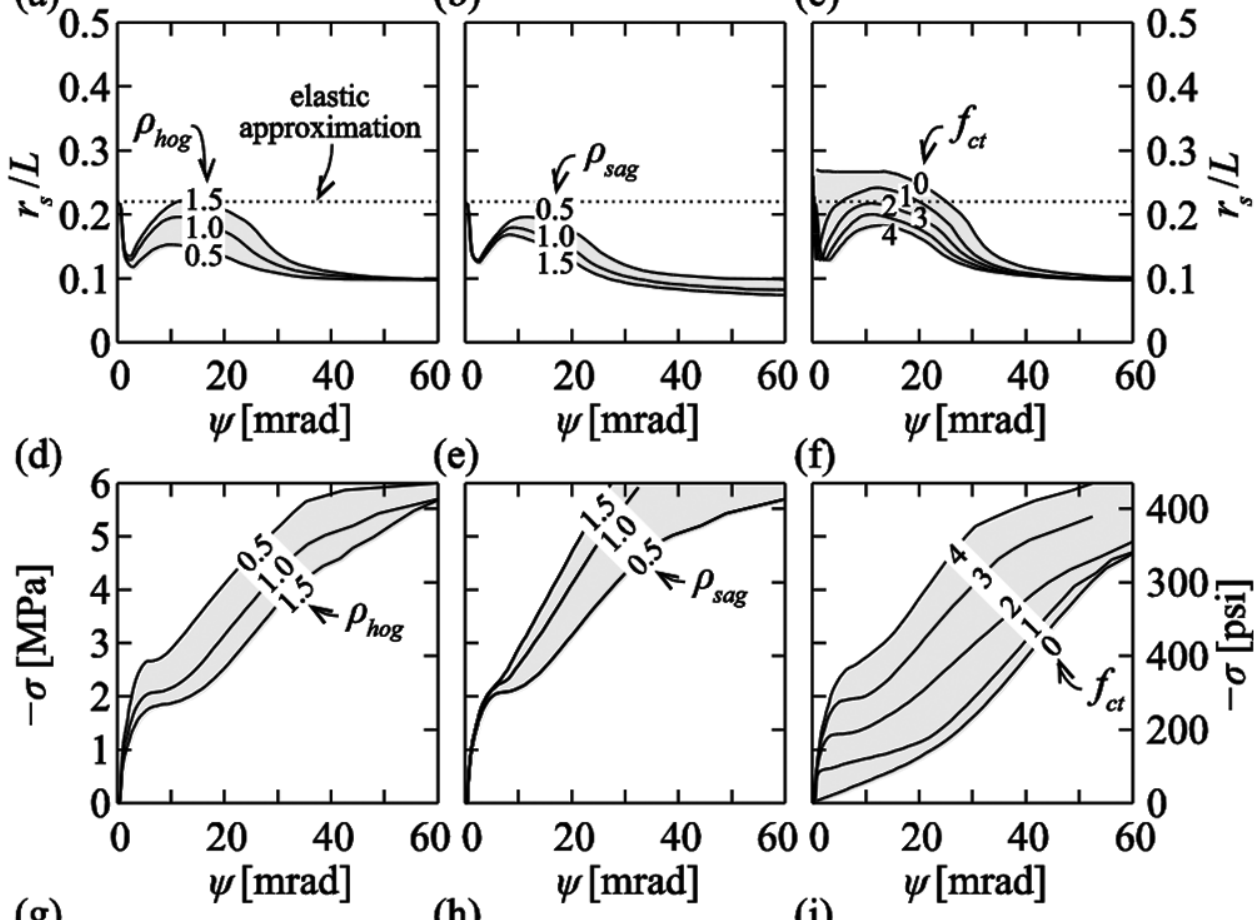

(f)
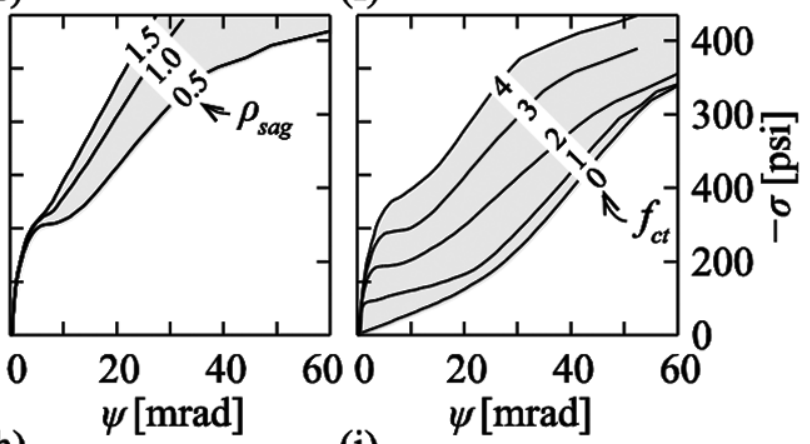

(g)

(h)
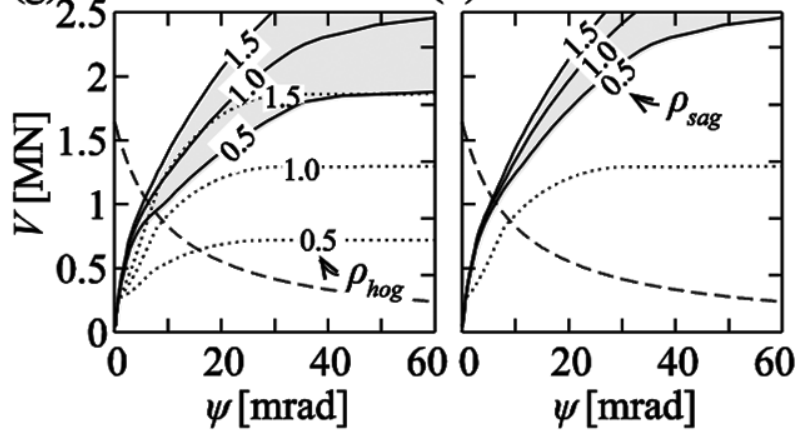

(i)

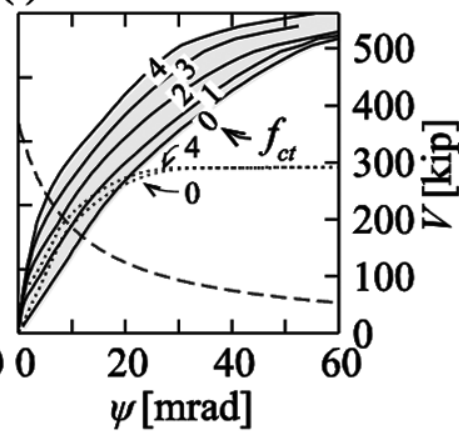

Parameters (if not shown otherwise):

$\rho_{\text {hog }}=1.0 \% ; \rho_{\text {sag }}=0.5 \% ; f_{c}=35 \mathrm{MPa}(5080 \mathrm{psi})$,

$f_{c t}=3.2 \mathrm{MPa}$ (460 psi), $d_{g}=16 \mathrm{~mm}$ (5/8 in.),

$f_{y}=420 \mathrm{MPa}(60.9 \mathrm{ksi}), L=7 \mathrm{~m}(23.0 \mathrm{ft})$;

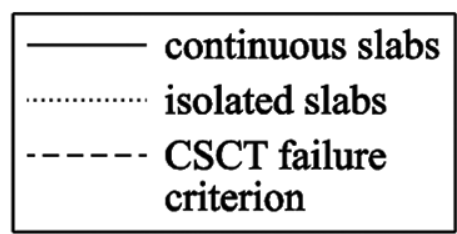

$c=0.35 \mathrm{~m}$ (13.8 in.); $d=0.21 \mathrm{~m}$ (8.27 in.);

$h=0.25 \mathrm{~m}$ (9.84 in.)

Fig. 11-Parametric analysis on continuous self-confined slabs in comparison to isolated specimens: (a) through (c) influence of $\rho_{\text {hog }}(\%), \rho_{\text {sag }}(\%)$, and $\mathrm{f}_{\mathrm{ct}}(\mathrm{MPa})$ on position of line of moment contraflexure; (d) through (f) influence of $\rho_{\mathrm{hog}}(\%), \rho_{\mathrm{sag}}(\%)$, and $\mathrm{f}_{\mathrm{ct}}(\mathrm{MPa})$ on development of compressive stresses in perimeter of column; and $(\mathrm{g})$ through (i) influence of $\rho_{\mathrm{hog}}(\%), \rho_{\mathrm{sag}}(\%)$, and $\mathrm{f}_{\mathrm{ct}}(\mathrm{MPa})$ on load-rotation curves. (Note: $1 \mathrm{MPa}=145 \mathrm{psi}$.)

$$
\begin{gathered}
\psi_{s-c}=\left(1-\frac{2 \cdot m_{c r}}{m_{R, h o g}}\right) \cdot \psi \\
=\left(1-\frac{2 \cdot m_{c r}}{m_{R, h o g}}\right) \cdot 1.5 \cdot \frac{r_{s}}{d} \frac{f_{y}}{E_{s}} \cdot\left(\frac{m_{S, h o g}}{m_{R, h o g}}\right)^{3 / 2}
\end{gathered}
$$

In Eq. (4), the influence of the tensile strength of concrete on the behavior of self-confined slabs (refer to the reduction of slab rotation with increasing $f_{c t}$ in Fig. 11(i)) is accounted for by considering the concrete cracking moment $m_{c r}$, which should be calculated using a value of concrete tensile strength that can be activated by tension stiffening of the tension ring in the crack development stage (normally the average value $f_{c t m}$ can be used ${ }^{23}$ ). As the assumptions used to derive the equation are only valid when the hogging moment capacity $m_{R, h o g}$ is clearly larger than the cracking moment $m_{c r}$, a minimum value for the factor $\left(1-2 m_{c r} / m_{R, h o g}\right)$ is set to 0.4 .

Equation (4) accounts both for the changes in the location of the line of moment contraflexure as well as the influence of CMA. This equation is thus valid for self-confined slabs without any external restraining elements. If a slab is 
(a)

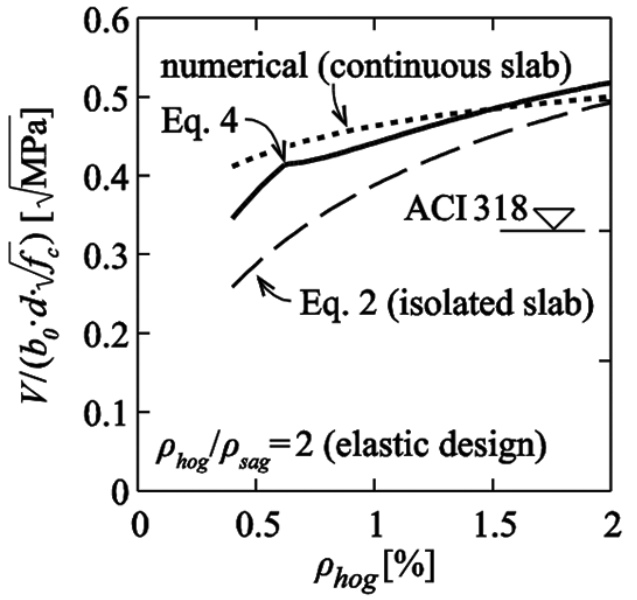

(d)

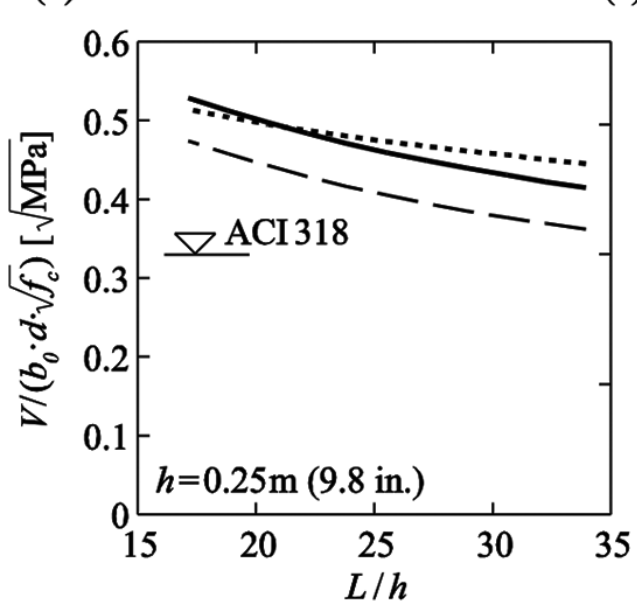

(b)

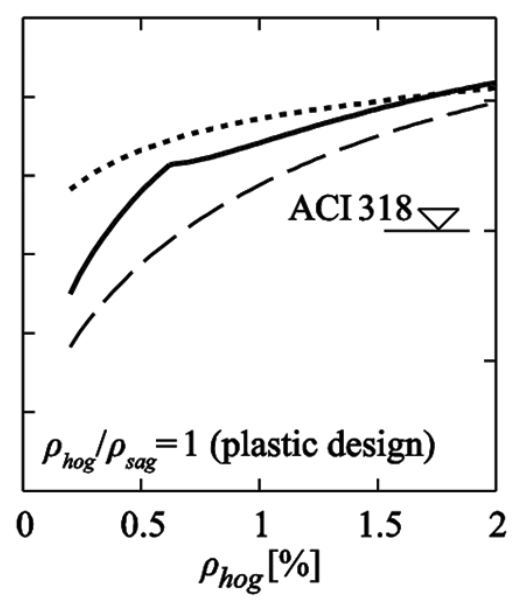

(c)

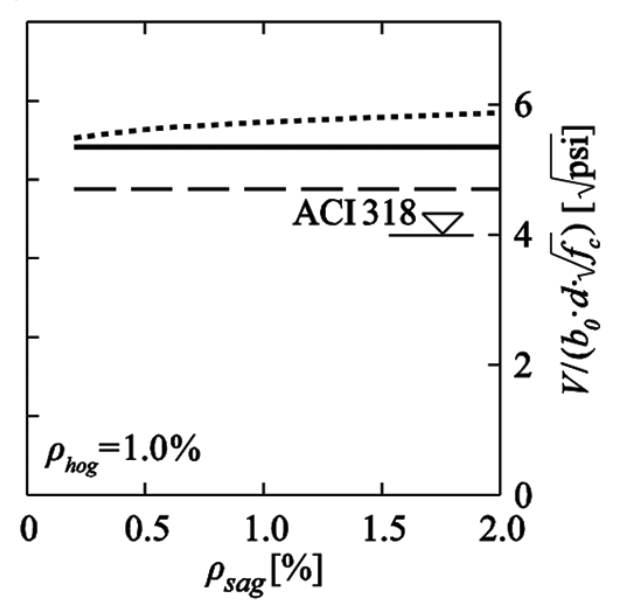

(e)

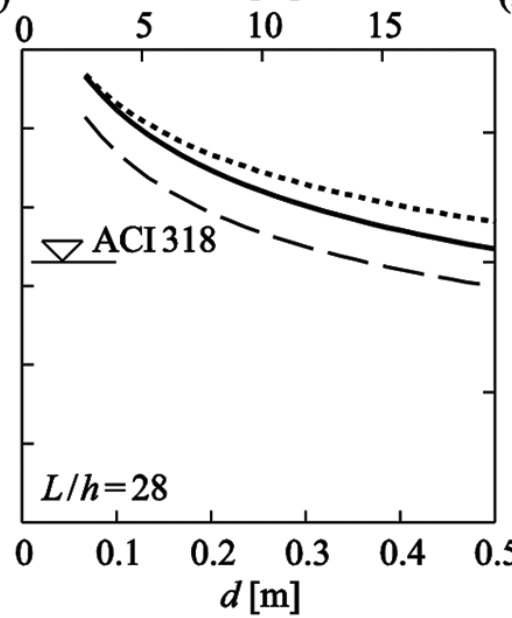

(f)

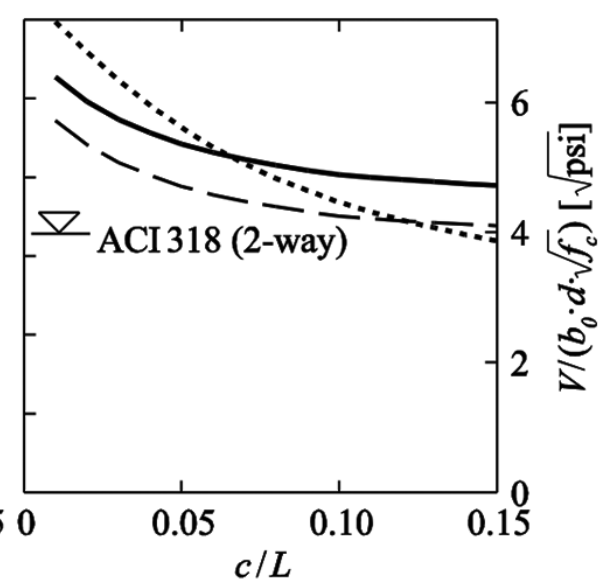

Parameters (if not shown otherwise): $\rho_{\text {hog }}=1.0 \% ; \rho_{\text {sag }}=0.5 \% ; f_{c}=35 \mathrm{MPa}(5080 \mathrm{psi}) ; f_{c t}=3.2 \mathrm{MPa}(460 \mathrm{psi}) ; d_{\mathrm{g}}=16 \mathrm{~mm}$ (5/8 in.); $f_{y}=420 \mathrm{MPa}$ (60.9 ksi); $L=7 \mathrm{~m}$ (23.0ft); $c=0.35 \mathrm{~m}$ (13.8 in.); $d=0.21 \mathrm{~m}$ (8.27 in.); $h=0.25 \mathrm{~m}$ (9.84 in.)

Fig. 12-Comparison of punching strengths calculated with load-rotation relationships from Model Code 2010 (dashed line), proposed expression (continuous line), and numerical model (dotted line): (a) and (b) influence of hogging reinforcement ratio; (c) influence of sagging reinforcement ratio; (d) influence of slab slenderness with constant h (slenderness effect); (e) influence of effective depth with constant slenderness (size effect); and (f) influence of column size.

confined between stiff horizontal supports, its rotation can be smaller than that of a self-confined slab. On the other hand, stiff horizontal supports may also restrain concrete shrinkage and cause tensile in-plane strains or concrete cracking in the slab that can reduce or completely hinder the effect of CMA. These tensile stresses can be accounted for in design by reducing the tensile strength of concrete that decreases the cracking moment in Eq. (4). In these cases, the loadrotation relationship may still account for possible redistribution between hogging and sagging moments (Curve 3 in Fig. 4(a)). However, considering that without CMA the stiffness of the sagging mechanism is lower than the stiffness of the hogging mechanism, using Eq. (3) (that Eq. (4) tends to with $m_{c r} \rightarrow 0$ ) can give a suitable approximation (refer to Curve 3 in Fig. 3(a)).

\section{Comparison between simplified and numerical approaches}

Figure 12 compares the punching strengths of self-confined slabs calculated with Eq. (4) with those determined using load-rotation relationships from the numerical model. Predictions for corresponding isolated specimens (radius of specimens $0.22 \mathrm{~L}$, load-rotation curve determined with Eq. (2)) are also shown. All the strengths are calculated in combination with the failure criterion given by Eq. (1). The punching strength estimate of ACI 318 is also shown.

Figures 12(a) and (b) show the influence of hogging reinforcement ratio on the punching capacity of slab-column connections. Experiments on isolated specimens have shown that increasing the amount of hogging reinforcement increases the punching strength. Following this observation, flexural reinforcement ratio in the vicinity of the column is taken into account in the punching provisions of several codes of practice ${ }^{23,28}$ (although it is neglected in ACI $318^{1}$ ). The present analysis indicates, consistently with the exper- 
imental observations of Choi and Kim, ${ }^{7}$ that the amount of hogging reinforcement has a lower influence on the punching capacity in continuous slabs than in isolated specimens. This can be explained by the fact that the influence of CMA and the contribution of sagging reinforcement are both more significant in the case of low amounts of hogging reinforcement, considerably increasing the flexural stiffness of such slabs (as seen by comparing the continuous and dotted load-rotation curves in Fig. 11(g)). The proposed formula for continuous self-confined slabs (Eq. (4)) increases the predicted punching shear strength of slabs with low reinforcement ratios and can be of particular interest for assessment of existing slabs. The constant punching shear strength used in ACI $318^{1}$ is seen to be conservative for all the considered reinforcement ratios.

The amount of sagging reinforcement has an important influence on the flexural strength but a significantly lower impact on the stiffness of a continuous slab (Fig. 11(h)). This is explained by the fact that the in-plane force in the tension ring (that induces CMA in the hogging moment area) is normally governed by tensile stresses of concrete and not by the amount of reinforcement in the tension ring. Therefore, the stiffness enhancement of the slab on lower levels of load is not significantly affected by the sagging reinforcement ratio. Thus, as shown in Fig. 12(c), the influence of this parameter on punching strength is limited and neglecting it in the simplified formula (Eq. (4)) is justified.

Figures 12(d) through (f) show the influence of different geometrical parameters on the punching shear strength of self-confined slabs in light of the proposed model. The slenderness effect ${ }^{21}$ that exists in isolated specimens is shown to be also present in continuous slabs in Fig. 12(d). According to this, when the slab depth and column size are kept constant, the punching shear strength of the slab-column connection decreases with increasing the slab span. The influence of size effect in the analyzed models (with respect to slab depth) is shown in Fig. 12(e). The depth of the slab as well as slab span are varied (with a constant slab slenderness $L / h=28$ ), while the column size is kept constant. It can be seen that the unitary shear strength of the control section decreases as $d$ increases. Accounting for the size effect is especially important for the cases where predictions for actual structures are made on the basis of experiments performed on reduced-scale models. The proposed approach considers the size effect similarly to Model Code $2010^{23}$ because it is taken into account in the failure criterion of CSCT (Eq. (1)). ACI $318^{1}$ does not account for the size effect and provides conservative predictions for thinner slabs.

Figure 12(f) shows the influence of column size on the punching shear strength. Whereas the total punching capacity of a slab-column connection increases with column size, the unitary strength on the control perimeter decreases according to the CSCT because a higher total load leads to larger rotations and wider cracks around the column (note that the column size does not influence slab rotation in the simplified Eq. (3) and (4)). The difference between the numerical and the simplified models is caused by the assumption made in the simplified approaches that the size of the hogging moment area is independent of column size $\left(r_{s}=0.22 L\right)$. In the numerical model, $r_{s}$ increases with increasing column size, leading to larger rotations and lower unitary punching strengths. In the punching provisions of ACI $318,{ }^{1}$ the influence of column size on the unitary shear strength is only accounted for very large columns (providing a transition from two-way to one-way shear strength), which is outside of the range of the present parametric study. For small columns, the predictions of ACI 318 are conservative.

\section{SUMMARY AND CONCLUSIONS}

Experimental, numerical, and analytical studies on punching strength of interior flat slab-column connections without transverse reinforcement indicate that:

1. As confirmed by experimental evidence, the response of continuous flat slabs is influenced by the effects of redistribution between hogging and sagging moments and compressive membrane action (CMA), often leading to smaller deformations and higher punching capacities than observed in the specimens that represent isolated hogging moment areas.

2 . The proposed axisymmetric nonlinear numerical model can accurately predict the flexural response of test slabs with restrained edge rotations. Using this model in combination with the failure criterion of CSCT provides a good estimate of a slab's punching shear capacity.

3. Edge-restrained specimens are better suited for modeling punching behavior of continuous flat plates than isolated test specimens. Presented experiments and their comparison to a numerical model provide evidence of CMA in test specimens with rotational restraint but without in-plane confinement.

4. The development of empirical design formulas for punching shear using test results from isolated slabs is believed to be conservative. However, the provisions for more precise calculations (such as for assessment of existing structures) should take into account the experimental and analytical evidence obtained from tests on slabs with flexural edge restraints.

5. The load-rotation curve of Model Code 2010 can be easily modified to take into account the stiffness and strength enhancement due to moment redistribution and CMA in self-confined continuous slabs. A simplified code-like formula is presented that leads to results that are similar to the ones obtained from the numerical analysis.

\section{AUTHOR BIOS}

Jürgen Einpaul is a Structural Engineer at Estkonsult in Tallinn, Estonia. He received his PhD from École Polytechnique Fédérale de Lausanne (EPFL), Lausanne, Switzerland, in 2016. His research interests include the mechanics of axisymmetric and non-axisymmetric punching shear failures of reinforced concrete slabs and the behavior of continuous slabs.

Carlos E. Ospina, FACI, is BergerABAM Inc.'s Houston Office Manager, where he is involved in the planning, design, and construction support of marine infrastructure projects. He is Co-Chair of ACI Subcommittee 445-C, Shear and Torsion-Punching Shear, and a member of ACI Subcommittee 318-F, Foundations (Structural Concrete Building Code).

Miguel Fernández Ruiz is a Senior Lecturer and Research Scientist in the School of Architecture, Civil, and Environmental Engineering (ENAC) at EPFL. He was the co-recipient of the ACI Wason Medal for the Most Meritorious Paper in 2014. His research interests include the serviceability behavior of structures, bond, shear and punching shear, and the modeling of structural concrete using stress fields. 
ACI member Aurelio Muttoni is a Professor and Head of the Structural Concrete Laboratory at the EPFL-ENAC. He was the recipient of the ACI Chester Paul Siess Award for Excellence in Structural Research in 2010 and co-recipient of the ACI Wason Medal for the Most Meritorious Paper in 2014. His research interests include the theoretical bases of the design of reinforced concrete structures, shear and punching shear, fiber-reinforced high-strength concrete, soil-structure interaction, and the conceptual design of bridges.

\section{ACKNOWLEDGMENTS}

The work presented in this paper was in part funded by the Swiss National Science Foundation (Project No. 200021 137658). Financial support for the slab test reported herein was provided to the second author by the ISIS Canada Network and by the National Science and Engineering Research Council of Canada (NSERC). The authors would like express their sincere gratitude for the support received.

\section{NOTATION}

As $\quad=$ cross section area of reinforcing bar

$b_{0} \quad=$ perimeter of critical section at $d / 2$ from column

$c \quad=$ side length or diameter of column

$d \quad=$ effective depth of slab (distance from tension reinforcement to extreme compressed fiber)

$d_{\text {bot }}=$ effective depth of bottom reinforcement of slab

$d_{g} \quad=$ maximum diameter of aggregate

$d_{g 0} \quad=$ reference aggregate size $(16 \mathrm{~mm}$ [0.63 in.])

$d_{\text {top }} \quad=$ effective depth of top reinforcement of slab

$E_{s} \quad=$ modulus of elasticity of reinforcement

$f_{c} \quad=$ average compressive strength of concrete (cylinder)

$f_{c t} \quad=$ tensile strength of concrete

$f_{c t m} \quad=$ mean value of tensile strength of concrete (taken as $f_{c t m}=$ $0.3 f_{c}^{2 / 3}[\mathrm{MPa}], f_{c t m}=1.6 f_{c}^{2 / 3}$ [psi], according to Model Code 2010 , if not shown otherwise)

$f_{y} \quad=$ yield strength of reinforcement

$h \quad=$ slab thickness

$L \quad=$ distance between axes of columns in continuous slab (slab span)

$m \quad=$ bending moment per unit width

$m_{c r} \quad=$ cracking moment per unit width

$m_{R} \quad=$ moment capacity per unit width

$m_{R, h o g} \quad=$ hogging moment capacity per unit width

$m_{R, s a g} \quad=$ sagging moment capacity per unit width

$m_{\text {rad }} \quad=$ radial bending moment per unit width

$m_{S, h o g} \quad=$ acting hogging moment per unit width due to applied load

$m_{S, s a g} \quad=$ acting sagging moment per unit width due to applied load

$n_{\text {edge }} \quad=$ in-plane applied force at edge of slab specimen, per unit width

$r_{c} \quad=$ column radius

$r_{q} \quad=$ distance between center of column and point of application of load

$r_{s} \quad=$ distance between center of column and line of moment contraflexure

$r_{\text {slab }}=$ distance between center of column and symmetry line in midspan of slab

$\begin{array}{ll}V & =\text { shear force } \\ V_{\text {flex, beam }} & =\text { shear force }\end{array}$

$V_{\text {flex,beam }}=$ shear force in center of beam at flexural capacity

$V_{\text {fex }, \text { cont }}=$ shear force at flexural capacity of continuous slab

$V_{\text {flex, }, \text { sol }}=$ shear force at flexural capacity of isolated slab

$V_{\text {flex },-c}=$ shear force at flexural capacity of self-confined continuous slab, CMA accounted for

$V_{R} \quad=$ punching shear capacity

$w \quad=$ maximum vertical displacement (deflection) of slab

$\rho=$ flexural reinforcement ratio

$\rho_{\text {hog }}\left(\rho_{\text {top }}\right)=$ hogging (top) reinforcement ratio

$\rho_{\text {sag }}\left(\rho_{\text {bot }}\right)=$ sagging (bottom) reinforcement ratio

$\sigma \quad=$ average axial stress in cross section

$\chi \quad=$ curvature

$\chi_{y} \quad=$ curvature at onset of flexural yielding

$\psi=$ rotation of slab at line of moment contraflexure

$\psi_{\text {edge }}=$ rotation of edge of slab specimen

$\psi_{R} \quad=$ rotation of slab at line of moment contraflexure at punching failure

$\psi_{s-c}=$ rotation of self-confined slab at line of moment contraflexure

$\psi_{y, \text { beam }}=$ rotation of beam at flexural limit

$\psi_{y, \text { isol }}=$ rotation of isolated slab at flexural limit

$\psi_{y, \text { cont }}=$ rotation of continuous slab at flexural limit, without CMA $\psi_{y, s-c}=$ rotation of self-confined continuous slab at flexural limit, with CMA

\section{REFERENCES}

1. ACI Committee 318, "Building Code Requirements for Structural Concrete (ACI 318-14) and Commentary (ACI 318R-14)," American Concrete Institute, Farmington Hills, MI, 2014, 519 pp.

2. Long, A. E., and Masterson, D. M., "Improved Experimental Procedure for Determining the Punching Strength of Reinforced Concrete Flat Slab Structures," Shear in Reinforced Concrete, SP-42, American Concrete Institute, Farmington Hills, MI, 1974, pp. 921-935.

3. Ladner, M.; Schaeidt, W.; and Gut, S., "Experimentelle Untersuchungen an Stahlbeton-Flachdecke," Bericht No. 205, EMPA, Switzerland, 1977, 96 pp. (in German)

4. Regan, P. E., "Symmetric Punching of Reinforced Concrete Slabs," Magazine of Concrete Research, V. 38, No. 136, 1986, pp. 115-128. doi: 10.1680/macr.1986.38.136.115

5. Alexander, S. D. B., and Simmonds, S. H., "Tests of Column-Flat Plate Connections," ACI Structural Journal, V. 89, No. 5, Sept.-Oct. 1992, pp. 495-502.

6. Chana, B. S., and Desai, S. B., "Membrane Action, and Design against Punching Shear," The Structural Engineer, V. 70, No. 19, 1992, pp. 339-343.

7. Choi, J.-W., and Kim, J.-H. J., "Experimental Investigations on Moment Redistribution and Punching Shear of Flat Plates," ACI Structural Journal, V. 109, No. 3, May-June 2012, pp. 329-338.

8. Einpaul, J.; Fernández Ruiz, M.; and Muttoni, A., "Influence of Moment Redistribution and Compressive Membrane Action on Punching Strength of Flat Slabs," Engineering Structures, V. 86, 2015, pp. 43-57. doi: 10.1016/j.engstruct.2014.12.032

9. Belletti, B.; Walraven, J. C.; and Trapani, F., "Compressive Membrane Action in Confined RC and SFRC Circular Slabs," Engineering Structures, V. 95, 2015, pp. 25-39. doi: 10.1016/j.engstruct.2015.03.043

10. Soares, L. F. S., and Vollum, R. L., "Comparison of Punching Shear Requirements in BS 8110, EC2, and MC2010," Magazine of Concrete Research, V. 67, No. 24, 2015, pp. 1315-1328. doi: 10.1680/macr.14.00432

11. Alexander, S. D. P., "Strip Design for Punching Shear," Design of Two-Way Slabs, SP-183, T. C. Shaeffer, ed., American Concrete Institute, Farmington Hills, MI, 1999, pp. 161-181.

12. Wood, R. H., Plastic and Elastic Design of Slabs and Plates, Thames and Hudson, UK, 1961, 344 pp.

13. Rankin, G. I. B.; Niblock, R. A.; Skates, A. S.; and Long, A. E., "Compressive Membrane Action Strength Enhancement in Uniformly Loaded, Laterally Restrained Slabs," The Structural Engineer, V. 69, No. 16, UK, 1991, pp. 287-295

14. Braestrup, M. W., and Morley, C. T., "Dome Effect in RC Slabs: Elastic-Plastic Analysis," Journal of the Structural Division, ASCE, V. 106, No. 6, 1980, pp. 1255-1262.

15. UK Highway Agency, BD 81/02, "Use of Compressive Membrane Action in Bridge Decks, Design Manual for Roads and Bridges," V. 3, Section 4, Part 20, UK, 2002, 20 pp.

16. Eyre, J. R., "Surround Stiffness to Membrane Action in Concrete Slabs," Magazine of Concrete Research, V. 59, No. 2, 2007, pp. 107-119. doi: 10.1680/macr.2007.59.2.107

17. Joint ACI-ASCE Task Committee 426 on Shear and Diagonal Tension, "The Shear Strength of Reinforced Concrete Members - Slabs," Journal of the Structural Division, ASCE, V. 100, No. ST8, VA, 1980, pp. 1543-1591.

18. Kinnunen, S., and Nylander, H., Punching of Concrete Slabs without Shear Reinforcement, Transactions of the Royal Institute of Technology, No. 158, Sweden, 1960, 112 pp.

19. Shehata, I. A. E. M., and Regan, P. E., "Punching in RC Slabs," Journal of Structural Engineering, ASCE, V. 115, No. 7, 1989, pp. 17261740. doi: 10.1061/(ASCE)0733-9445(1989)115:7(1726)

20. Broms, C. E., "Punching of Flat Plates-A Question of Concrete Properties in Biaxial Compression and Size Effect," ACI Structural Journal, V. 87, No. 3, May-June 1990, pp. 292-304.

21. Muttoni, A., "Punching Shear Strength of Reinforced Concrete Slabs without Transverse Reinforcement," ACI Structural Journal, V. 105, No. 4, July-Aug. 2008, pp. 440-450.

22. Fernández Ruiz, M.; Muttoni, A.; and Sagaseta, J., "Shear Strength of Concrete Members without Transverse Reinforcement: A Mechanical Approach to Consistently Account for Size and Strain Effects," Engineering Structures, V. 99, 2015, pp. 360-372. doi: 10.1016/j.engstruct.2015.05.007

23. Fédération internationale du béton, "fib Model Code for Concrete Structures 2010," Ernst and Sohn, Germany, 2013, 434 pp. 
24. Ospina, C. E.; Alexander, S. D. B.; and Cheng, J. J. R., "Behaviour of Concrete Slabs with Fibre-Reinforced Polymer Reinforcement," Structural Engineering Report No. 242, Department of Civil and Environmental Engineering, University of Alberta, Edmonton, AB, Canada, 2001, 355 pp.

25. Clément, T.; Pinho Ramos, A.; Fernández Ruiz, M.; and Muttoni, A., "Influence of Prestressing on the Punching Strength of Post-Tensioned Slabs," Engineering Structures, V. 72, 2014, pp. 56-69. doi: 10.1016/j. engstruct.2014.04.034

26. ACI Committee 318, "Building Code Requirements for Reinforced Concrete (ACI 318-71) and Commentary," American Concrete Institute, Farmington Hills, MI, 1971, 78 pp.

27. CSA A23.3-M94, "Design of Concrete Structure for Buildings," Canadian Standards Association, Mississauga, ON, Canada, 1994, 199 pp.
28. "Eurocode 2: Design of concrete structures-Part 1: General rules and rules for buildings," European Committee for Standardization (CEN), Brussels, Belgium, 2004, 225 pp.

29. Natário, F.; Fernández Ruiz, M.; and Muttoni, A., "Experimental Investigation on Fatigue of Concrete Cantilever Bridge Deck Slabs Subjected to Concentrated Loads," Engineering Structures, V. 89, 2015, pp. 191-203. doi: 10.1016/j.engstruct.2015.02.010

30. Muttoni, A.; Fernández Ruiz, M.; Bentz, E. C.; Foster, S. J.; and Sigrist, V., "Background to the Model Code 2010 Shear Provisions-Part II Punching Shear," Structural Concrete, V. 14, No. 3, 2013, pp. 195-203. doi: $10.1002 /$ suco.201200064 